\title{
Ad nostram scientiam referatur: la supervisión administrativa imperial de la aplicación de las leyes durante la dinastía constantiniana
}

\author{
Esteban MORENO RESANO \\ Universidad de Zaragoza \\ estmores@unizar.es
}

Recibido: 23 de febrero de 2015

Aceptado: 14 de mayo de 2015

\section{RESUMEN}

Constantino y sus sucesores, Constancio II, Constante y Juliano, expresaron su particular interés por supervisar la aplicación de determinadas leyes imperiales mediante el uso de la fórmula ad nostram scientiam referatur y de otras similares. Constantino fue el príncipe que la empleó con más frecuencia, especialmente durante el período de 313-324, exceptuando el intervalo de 315-316, cuando la confrontación con Licinio le obligó a renunciar a atender directamente las cuestiones administrativas. La progresiva disminución de la inclusión de estas cláusulas en los textos legales imperiales a partir de la unificación del Imperio en 324 se debe poner en relación con la aparición de los curiosi y luego de los agentes in rebus, como oficiales encargados de vigilar la observancia de las normas vigentes.

Palabras clave: Constantino. Constancio II. Constante. Juliano. Leyes. Administración imperial.

\section{Ad nostram scientiam referatur: The Imperial Administrative Supervision of the Execution of Laws during the Constantinian Dinasty}

\begin{abstract}
Constantine and his heirs, Constantius II, Constans, and later Julian, expressed their particular interest in the supervision of the application of certain imperial laws using the formula ad nostram scientiam referatur or another similar ones. Constantine was the prince who more often employed it, especially during the period of 313-324, apart from the interval of 315-316, when the confrontation with Licinius compelled him to give up the attention to administrative questions. The progressive decrease of the insertion of that clauses in the legal imperial texts from the unification of the Empire in 324 AD must be put in relation to the appearance of curiosi and later, the agentes in rebus, as officers put in charge of the observance of the acts in force.
\end{abstract}

Key words: Constantine. Constantius II. Constans. Julian. Laws. Imperial Administration.

Sumario: 1. Introducción. 2. La periodización de las intervenciones. 2.1. El primer período (313). 2.2. El segundo período (314-321). 2.3. El tercer período (324-331). 2.4. Las intervenciones de Constante y Constancio II. 2.5. El principado de Juliano. 3. Conclusiones. 
Ad nostram scientiam referatur: la supervisión administrativa...

\section{Introducción ${ }^{1}$}

Treinta y dos leyes imperiales libradas entre 313 y 362 contienen cláusulas que obligaban a magistrados públicos, oficiales de la administración, jueces y obispos a informar al príncipe acerca de la aplicación de determinadas medidas o de la instrucción de causas judiciales. Veinticinco están incluidas en normas de Constantino, cuatro en textos de Constancio II y tres en instrucciones de Juliano. La fórmula usada con mayor frecuencia es ad nostram scientiam referatur. No obstante, en ocasiones, en lugar de nostra scientia, aparecen otras expresiones análogas, como nostra conscientia, conspectus noster o deliberatio nostra. ${ }^{2}$ Honig explicó las distintas acepciones y connotaciones de estos términos desde el punto de vista semántico. ${ }^{3}$ El propósito de este trabajo es, sin embargo, analizar la evolución de su empleo en el contexto político de las transformaciones del principado en el siglo IV, con el fin de demostrar que sirvieron para el control imperial de la aplicación de las leyes y del funcionamiento de la burocracia durante la dinastía constantiniana.

La introducción de estas estipulaciones no fue una innovación adoptada por Constantino. Aparece con frecuencia en la correspondencia entre el príncipe y los gobernadores provinciales o jueces ordinarios desde finales del siglo I hasta comienzos del IV. Antes de la época constantiniana, su empleo respondía esencialmente a la necesidad de regular la intervención del emperador en asuntos judiciales, tal y como ha estudiado Arcaria. ${ }^{4} \mathrm{Su}$ finalidad era procurar información al príncipe acerca de los casos que debía examinar para que pudiera pronunciarse sobre ellos con suficiente

1 Este trabajo ha sido realizado gracias a la concesión de un Contrato de Investigación dentro del Subprograma "Ramón y Cajal" (Ministerio de Economía y Competitividad), y a la participación en el Proyecto de Investigación HAR2013-41470, financiado por el Ministerio de Economía y Competitividad, y en el Grupo Hiberus, subvencionado por el Gobierno de Aragón.

2 CTh. 12, 1, 1 (Br. 12, 1, 1; CI. 10, 32, 14 -313-): (...) ad nostram scientiam referri oportet (...); CTh. 11, 30, 1 (313): (...) debebis (...) omnia ad nostram scientiam referre; Euseb. Caes., HE, 10, 5, 17 (313); CTh. 11, 36, 1 (313): deliberationi nostrae plenum arbitrium relinquatur; Opt. Mileu., App. 3 (Ad Aelafium): (...) cuncta ad scientiam meam etiam actis habitis retulerunt (...); CTh. 7, 20, 2 (i316?): (...) ad sanctimoniam conspectus mei sine ulla deliberatione remittere (...); CTh. 9, 1, 1 (Br. 9, 1, 1 -317-): (...) neque (...) ad scientiam nostram referatur (...); CTh. 11, 30, 8 (319): (...) ad comitatum nostrum properantissime volumus adferri (...); CTh. 11, 30, 9 (319): Ne causas, quae in nostram venerint scientiam rursus ad iudicia transferre sit (...); CTh. 9, 21, 1 (321): (...) ad nostram scientiam referatur (...); CTh. 4, 9, 1 (CI. 7, 10, 7 -319-): (...) in conspectu nostro (...) monstrabitur (...); CTh. 11, 29, 2 (319): (...) nostram consulat scientiam (...); CTh. 9, 34, 3 (320): (...) nec (...) ad nostram scientiam referendum (...); CTh. 16, 10, 1 (320): (...) ad nostram scientiam referatur (...); CTh. 2, 18, 1 (321): (...) ad nostram scientiam referenda (...); CTh. 15, 1, 2 (321): (...) diversos misimus qui ad scientiam nostram referant (...) ad nostram scientiam referant; CTh. 1, 5, 1 (325): (...) ad scientiam nostram referat gravitas tua (...); Euseb. Caes., VC, III, 53, 2; Euseb. Caes., VC, III, 31, 3; CTh. 10, 8, 3 (Br. 10, 4, 1 -326-): (...) ad nostram scientiam referendis (...); CTh. 1, 16, 4 (328): (...) ad nos aut certe ad gravitatis tuae scientiam referre (...); CTh. 11, 30, 13 (326 ó 329): (...) ad nostram referre clementiam (...); CTh. 11, 30, 18 (329 ó 339): (...) ad nostram scientiam referantur (...); CTh. 1, 16, 6 (331): (...) ad nostram scientiam referentibus (...); CTh. 1, 15, 2 (348): (...) aliquid scientiae nostrae relatum cupiunt (...); CTh. 11, 16, 8 (CI. 10, 48, 8 -357 ó 358-): (...) referri ad scientiam nostram (...); CTh. 6, 29, 3 (359): (...) si ad serenitatis nostrae notitiam (...) gesta pervenerint (...); CTh. 14, 1, 1 (357 ó 360): (...) ut deliberemus (...); CTh. 11, 16, 10 (362): Nihil (...) sine nostra scientia (...); CTh. 1, 15, 4 (362): ad nos et ad vestram scientiam crediderint referendos (...); CTh. 8, 5, 14 (362): (...) ad serenitatis nostrae conscientiam referendum est (...).

3 Honig 1960, 121-126.

4 ARCARIa 2000. 
conocimiento de causa. Así lo atestigua una carta que dirigió Marco Aurelio al procurador de Tingitana, conservada en la llamada Tabula Banasitana. El documento en cuestión hacía relación a la concesión de la ciudadanía romana a la esposa e hijos del jefe de la tribu de los Zegrenses con la siguiente indicación: Quod ut in commentarios nostros referri / possit, explora quae cuiusq(ue) aeta<ti $>$ s sit, et scribe nobis. ${ }^{5}$ De acuerdo con ella, el emperador requería más datos para argumentar su resolución, figurando en su respuesta. Fue después de que el Senado reconociera a Constantino como Augusto, en 312, cuando estas prescripciones pasaron a ser empleadas por los príncipes para comprobar y supervisar personalmente el cumplimiento de algunas medidas.

La mayor parte de estas fórmulas (en número de diecinueve) atañen a instrucciones judiciales. ${ }^{6}$ Otras catorce trataban de verificar la aplicación de leyes imperiales. ${ }^{7}$ Cabe plantearse si estas solicitudes eran requerimientos imperiales reales o bien expresiones protocolarias. El quaestor sacri palatii asumió la competencia de redactar las leyes desde época de Valentiniano I. ${ }^{8}$ No obstante, existen evidencias de que los príncipes de la dinastía constantiniana intervenían en la elaboración de los textos normativos. Constantino supervisaba la observancia de algunas medidas. Es la carta dirigida en 320 al prefecto de Roma Máximo, a propósito de las interpretaciones de prodigios por parte del colegio de los harúspices, el emperador no sólo le solicitaba los informes que concernieran a tal particular, sino que, además, le comunicaba que ya había recibido una misiva relativa al impacto de un rayo sobre el anfiteatro flavio. La carta en cuestión había sido dirigida por Máximo al magister officiorum Heracliano, máximo responsable de la administración palatina, quien, en esta calidad, se la había hecho llegar a Constantino. ${ }^{9}$ Pero no fue él quien redactó ni esa carta ni ninguna de las leyes. Esa tarea correspondía en época constantiniana a los notarii, que eran quienes ponían por escrito las palabras del príncipe, según las dictaba asistido por su consilium formado por comites ${ }^{10}$ En todo caso, los encargados de los scrinia, bajo la dirección del magister officiorum, eran los responsables tanto de la forma definitiva de los textos imperiales como de su tramitación con fin de hacerlos aplicar. ${ }^{11}$

Aunque Constantino y sus sucesores atendían selectivamente algunos asuntos, que eran identificados con las cláusulas estudiadas, la vigilancia de otros estaba encomendada a oficiales civiles. Se tiene noticia desde el año 335 de la existencia de los curiosi, oficiales que debían atender el buen funcionamiento del cursus publicus, pero que también actuaban como inspectores administrativos al servicio de los em-

5 Inscriptions Antiques du Maroc, II, 94. Cf. Christol 1988.

6 CTh. 12, 1, 1 (Br. 12, 1, 1; CI. 10, 32, 14); CTh. 11, 30, 1; Opt. Mileu., App. III; CTh. 11, 36, 1; CTh. 9, 1, 1 (Br. 9, 1, 1); CTh. 11, 30, 8; CTh. 4, 9, 1 (CI. 7, 10, 7); CTh. 11, 30, 9; CTh. 9, 34, 3; CTh. 2, 18, 1; CTh. 15, 1, 2; CTh. 1, 5, 1; CTh. 1, 16, 4 (CI. 1, 40, 2); CTh. 10, 8, 3 (Br. 10, 4, 1); CTh. 11, 30, 18; CTh. 11, 30, 13; CTh. 11, 30, 16; CTh. 1, 15, 2; CTh. 11, 16, 8 (CI. 10, 48, 8).

7 Euseb. Caes., HE, 10, 5, 17; CTh. 7, 20, 2; CTh. 11, 29, 2; CTh. 16, 10, 1; Euseb. Caes., VC, III, 53, 2; Euseb. Caes., VC, III, 31, 1; CTh. 1, 16, 6 (CI. 1, 40, 3); CTh. 14, 1, 1; CI. 12, 1, 5; CTh. 6, 29, 3-4; CTh. 11, 16, 10; CTh. 1, 15, 4; CTh. 8, 5, 14.

8 HARRIES 1988.

9 CTh. XVI, 10, 1.

10 Amelotti 1975, 20; De Bonfils 1981, 72.

11 Millar 1977, 77. 
peradores. ${ }^{12}$ Con Constancio II y Juliano, sin embargo, hubo algunas modificaciones significativas por lo que se refiere a los procedimientos. Los notarii, como personas de confianza del príncipe, asumieron otras funciones, entre otras, la inspección de los movimientos de las tropas. ${ }^{13}$ Se trataban éstas de comisiones extraordinarias que les eran encomendadas por los Augustos. ${ }^{14}$ Los comites et quaestores, que acompañaban y vigilaban a los césares Galo y Juliano, contaban entre sus funciones la de verificar el cumplimiento de los designios imperiales. ${ }^{15} \mathrm{La}$ introducción de estos cargos, unida a la ampliación de las competencias de los agentes in rebus, apartaba a los sucesores de Constantino de la gestión directa de los asuntos burocráticos. ${ }^{16}$ De hecho, Constancio II y Juliano sólo exigieron ser informados de ciertas cuestiones ocasionalmente, $\mathrm{y}$, casi siempre, mediando la intervención de los agentes. Conviene señalar que ni la schola agentum in rebus ni los curiosi llevaban a cabo una labor sistemática de control de la gestión pública. ${ }^{17}$ Tal y como indicaba Purpura, su cometido primordial era la inspección del servicio de correos imperiales, circunstancia que aprovechaban para realizar otras tareas, entre otras, la vigilancia política. ${ }^{18}$ Ésta, en todo caso, según observaba Giardina, se concretó en recabar información acerca de posibles conspiraciones y en verificar el buen funcionamiento de la administración y el cumplimiento de las leyes. ${ }^{19}$

\section{La periodización de las intervenciones}

Partiendo de estas consideraciones, se ha de observar que estas medidas eran más bien coyunturales, ya que sólo se explican en función de unas circunstancias políticas muy concretas. En efecto, su uso se concentra en unos determinados espacios cronológicos, en concreto, en el bienio de 313-314 y el período de 316-321. Fueron éstos los intervalos durante los que Constantino y Licinio mantuvieron buenas relaciones. Entre 313 y 314, Constantino y Licinio se repartieron el Imperio a título de diarcas,

\footnotetext{
12 Ath. Alex., Apol. contra Ar., 74-75. Cf. Purpura 1973, 18-19.

13 Amm. Marc., 14, 5; 20, 4, 2; 21, 7, 2; 26, 5, 14; 28, 2, 5. Cf. Purpura 1973, 78, n. 175.

14 BABut 1914, 83-86.

15 De Bonfils 1981, 79-83.

16 Los agentes in rebus existían desde época constantiniana, pues están documentados en una ley de 319 (CTh. 6, 35, 2). A nuestro juicio, en ese momento no actuaban oficialmente como informadores del emperador. La ampliación de sus competencias, hasta comprender la vigilancia de la función pública y de sus empleados, se debió de producir después de que Constancio II derrotara a Magnencio en 353. Es posible que esta reforma se produjera ante la necesidad de modificar la administración imperial para regir las dos Partes Imperii. De hecho, las nuevas funciones de los agentes están atestiguadas en una ley de 355 (CTh. 6, 29, 1). Estas atribuciones quizás no eran nuevas, pero sí fueron reguladas entonces por las exigencias políticas del momento. Véase acerca de este último aspecto: SANTOS YANGUAS 1977, 128, 132.

17 A. Giardina (1977) identifica a los curiosi con los agentes in rebus. En realidad, de acuerdo con Purpura, los curiosi eran miembros de la schola agentum in rebus con el específico encargo de vigilar el funcionamiento del cursus publicus (PURPURA 1973, 25).

18 CTh. 6, 29, 2. Cf. Purpura 1973, 14-15, 24. La función que acabaron teniendo los agentes in rebus la desempeñaban desde época de Augusto los correos imperiales, quienes eran interrogados sobre la situación de las provincias por donde habían pasado si la ocasión la requería (Suet., Augustus, 49).

19 GiaRdina 1977, 71.
} 
tal y como pactaron en Milán, con un acuerdo sellado con el matrimonio entre Licinio y Constancia, hermana de Constantino. ${ }^{20}$ La concordia dejó de tener efecto a partir de 314, por el recíproco recelo que demostraban los Augustos. En 315 un nuevo conflicto agravó la situación: Licinio incitó a Basiano, también casado con una hermana de Constantino y que aspiraba al título de César, a levantarse en armas contra su cuñado. Después de que Constantino descubriera y frustrara la maniobra, ambos emperadores se enfrentaron primero en el Bellum Cibalense en 316. ${ }^{21}$ Poco después, combatieron de nuevo en Campus Ardiensis, cuyo indeciso desenlace trató de ser resuelto con la llamada Paz de Sérdica del año 317.22 En los lapsos de distensión de las relaciones entre los Augustos, Constantino, libre de preocupaciones estratégicas, políticas y familiares, pudo dedicarse a controlar personalmente la aplicación de las leyes.

Tras la definitiva derrota de Licinio después de la guerra civil de 324 y hasta la muerte de Constantino en 337, las cláusulas comentadas aparecen de modo más esporádico, pues sólo se conocen nueve casos. Puede relacionarse este hecho con la atribución a los prefectos del pretorio de facultades más amplias en materia de control administrativo. La supervisión directa de la burocracia era una tarea imposible para Constantino después de la unificación del Imperio bajo su autoridad, lo cual explica la progresiva transformación y definición de las funciones del prefecto del pretorio después de 324. Conviene también tener presente que estas provisiones no fueron libradas de modo espontáneo por el emperador. Todas ellas eran respuestas a consultas o solicitudes que le eran elevadas desde distintas instancias. En todo caso, las demandas de intervención imperial suscitaron en Constantino el interés por determinadas cuestiones que consideró de relevancia política.

\subsection{El primer período (313)}

La primera estipulación de Constantino que trataba de verificar la ejecución de un dispositivo legal apareció en una instrucción expedida en Tréveris el 3 de noviembre de 313, dirigida a Catulino, gobernador de Bizacena. En esta ocasión, las provisiones imperiales determinaban que los crímenes de homicidio, maleficio, adulterio o envenenamiento eran inapelables, salvo en los casos dudosos, cuya resolución correspondía exclusivamente al emperador. ${ }^{23} \mathrm{~A}$ finales de ese mismo año, otra ley, expedida en Tréveris el 30 de diciembre, dirigida al gobernador de Lucania y Brittii, trataba de regular la administración de justicia. Prescribía a los jueces un plazo máximo de quince días para dirigir al emperador consultas sobre querellas civiles. De ellos, hasta diez días estaban reservados para publicar el texto de la solicitud y otros cinco para que los litigantes pudieran alegar por carta sus objeciones. Transcurridos los quince días, el juez debería comunicarle la causa en el estado en el que se encontrara. ${ }^{24} \mathrm{Am}$ -

20 An. Val. (Origo), 13; Aurel. Vict., 41, 2; Eutrop., 10, 5; Zos., 2, 17, 2.

21 An. Val. (Origo), 14-16. El Bellum Cibalense fue datado erróneamente por Jerónimo en 313 (Hieron. Strid., Chron. CCLXXIII Olymp. VII).

22 An. Val. (Origo), 17. Sobre ambas batallas, véase: Di Maio - Zeuge - Bethune 1990; Maraval 2011, $142-144$.

23 CTh. 11, 36, 1. Cf. Dillon 2012, 237.

24 CTh. 11, 30, 1. 
bas provisiones demuestran que las intenciones de Constantino eran racionalizar el sistema judicial romano, evitando prolongar el curso de los procesos al determinar que no todos los recursos podían llegar a la corte, sino sólo aquellos que ofrecieran motivos suficientes y que se formularan dentro de un intervalo de tiempo previamente establecido. ${ }^{25}$

Como se puede comprobar, los asuntos de índole judicial merecieron particular atención por parte de Constantino desde que se hizo dueño de Occidente. También la recibieron las cuestiones eclesiásticas. Los Augustos habían acordado en Milán algunas medidas en beneficio de los cristianos comunes a las dos Partes Imperii. Licinio tenía interés en congraciarse con la importante comunidad cristiana de Nicomedia, algunos de cuyos más destacados miembros habían pertenecido a la corte imperial. Constantino, por su parte, actuó movido por su afecto personal hacia ellos y porque, después de la batalla de Puente Milvio, reconoció en Cristo a su protector personal, aunque todavía no a título monoteísta. ${ }^{26}$ En cualquier caso, Constantino no sólo aplicó las disposiciones milanesas, sino que prodigó privilegios al clero para ganarse su favor. ${ }^{27}$

De este modo, en una fecha indeterminada de 313, Constantino envió una carta a Anulino, procónsul de África, en la que le instaba a ser diligente en devolver los bienes a los cristianos, con el fin de que llegara a su conocimiento (se supone, por medio de la correspondencia de los obispos) que sus órdenes se habían cumplido. ${ }^{28}$ Al parecer, Anulino, después de recibir el texto de los acuerdos de Milán, que obligaba a devolver a las iglesias los bienes que se les hubieran confiscado durante las persecuciones, había escrito al emperador para verificar los términos del documento que había recibido. ${ }^{29}$ Tampoco dudó en intervenir en favor del clero católico cuando estalló la querella donatista. Fue informado a propósito de la misma por Anulino, a través de escritos (libelli) donde detallaba los particulares del caso para conocimiento del emperador. Éste, tomando parte por Ceciliano de Cartago, solicitó al obispo Milcíades de Roma que estableciera un tribunal eclesiástico en Roma, formado por Reticio de Autún, Materno de Tréveris y Marino de Arelate, para que juzgara la causa. ${ }^{30} \mathrm{~A}$ buen seguro, siguiendo indicaciones del propio Constantino, los obispos, concluido el proceso (que no fue aceptado por los donatistas), le enviaron sus actas canónicamente suscritas. ${ }^{31}$

Estas disposiciones estaban reservadas a los responsables de la administración imperial en las provincias. No eran medidas propagandísticas. Trataban, por el con-

25 Dillon 2012, 237. En el mismo sentido, a partir del comentario de CTh. 11, 30, 6, véase: DuPont 1971, 560.

26 Hemos analizado el proceso de conversión de Constantino en Moreno Resano 2013. Para otros puntos de vista sobre esta cuestión, cf. Elliott 1996; Van Dam 2003; Odahl 2004; Buenacasa Pérez 2011.

27 Sobre los privilegios procurados a los eclesiásticos, cf. GiRARDEt 2006, 146-152.

28 Euseb. Caes., $H E, 10,5,17$.

29 Lact., De mort. persec., 48, 7-8; Euseb. Caes., HE, 10, 5, 9. Sobre las estipulaciones en cuestión, cf. Christensen 1984, 155-157.

30 Euseb. Caes., HE, 10, 5, 18-20; Aug. Hipp., De unico bapt., 16, 28. Cf. GIRARDET 1992. Pietri y Christol han defendido que se trataba de un juicio imperial por delegación (Pietri 1978, 160-168; Christol 1988, 92). En rigor, se debe señalar que se trataba de un juicio eclesiástico celebrado por orden del emperador.

31 Opt. Mileu., App. 3. 
trario, de garantizar la ejecución de las leyes advirtiendo de que Constantino estaría informado de cada particular. La circulación de estos textos se limitó al ámbito burocrático. Sólo debió de tener difusión fuera de la administración la carta dirigida a Anulino, puesto que Eusebio de Cesarea la recoge en su Historia Ecclesiastica. Tenía que formar parte de una selección de normas constantinianas relativas a la Iglesia que circularon a modo de prontuario de la legislación vigente sobre materia eclesiástica entre los obispos de las dos Partes Imperii. ${ }^{32}$ Para entender estas resoluciones, ha de tenerse presente que Constantino se acababa de hacer en 313 con el dominio sobre todas las provincias occidentales después de derrotar a Majencio y de dividir el Imperio con Licinio. Se encontraba, por tanto, en la necesidad de poner orden en la administración y de mostrar a sus responsables cuál sería su modo de actuar en la gestión pública. Constantino no se presentaba en esos documentos como un príncipe reformista, sino como un atento político, que supervisaba la gestión de los gobernadores provinciales. En todo caso, cabe destacar que estas intervenciones plantean una novedad con relación a la época tetrárquica: frente a la libertad de actuación otorgada a los príncipes y gobernadores por Diocleciano, Constantino procuraba poner medios de control en la gestión de las provincias. ${ }^{33}$

\subsection{El segundo período (314-321)}

A partir de esas fechas se observan algunos indicios de intervenciones orientadas a realizar algunas reformas administrativas coyunturales. En 314, con miras a encontrar remedio al caótico cuerpo normativo romano, había comenzado a sancionar medidas que regulaban la recitatio de textos legales en procesos judiciales, haciendo prevalecer los rescripta y leges generales sobre las adnotationes en caso de contradicción. ${ }^{34}$ Un año más tarde otorgó primacía a los iura sobre los rescriptos imperiales en las mismas circunstancias. ${ }^{35}$ Además, entre 316 y 321, varias provisiones constantinianas tratarán de poner orden donde no lo había. No carecía de razones. Debía demostrar su capacidad de ser un buen gestor de los asuntos públicos para distinguirse de su competidor Licinio. En efecto, el emperador, cuando se encontraba en Galia en 316, antes de enfrentarse a su cuñado, atendió las quejas de algunos de sus veteranos que denunciaban haber sido presionados para asumir munera. Constantino les respondió ratificando su inmunidad fiscal, prescribiéndoles, además, que le hicieran saber si alguien les exigía prestaciones de servicio público. ${ }^{36}$ Las exenciones de este

32 Barone-Adesi 1998, 79-84; CARotenuto 2002.

33 Sobre la administración tetrárquica, véase KUHOFF 2001.

34 CTh. 1, 2, 1.

35 CTh. 1, 2, 2.

36 CTh. 7, 20, 2. La ley, tal y como está recogida en el Codex Theodosianus, está datada en 320. Esta fecha es incongruente, porque ese año Constantino no estaba en Galia. Tampoco puede ser de 325, como sugiere Gaudemet, porque los prefectos del pretorio reciben el tratamiento de eminentissimi viri, que en 324 fue sustituido por el clarissimi. Menos verosímil es que sea de 307, cuando Constantino todavía no había sido reconocido como Augusto. Sólo puede ser, en consecuencia, del año 316, cuando tres leyes le ubican en tierras galas. Cf. CTh. 1, 22, 1 (Tréveris); CTh. 9, 40, 2 (Cabullinum-Chalons-); CTh. 2, 6, 1 (Vienna); CTh. 11, 30, 5; CTh. 11, 30, 6 (Arelate). Véase al respecto: GAudemet 1982, 188-189; Barnes 1982, 73; CoRCORAN $1996,329$. 
tipo de servicios eran consideradas competencia exclusiva del emperador, y a él se le debía presentar cualquier reclamación relacionada con ellas, como estipuló posteriormente en $329 .{ }^{37}$ Los abusos de magistrados y oficiales trataron de ser remediados con otras intervenciones de este mismo período. Así, en 321, envió a Menandro, quizás en calidad de vicario de prefecto del pretorio de Italia en África, una disposición que le exigía velar porque los jueces que debían encargarse de la realización de las obras públicas le notificaran los trabajos realizados, por si fuera necesario nombrar a otros responsables de obras. Así mismo, le indica que, pues muchos jueces se habían comportado negligentemente ignorando las medidas imperiales, había enviado a personas para que le informaran acerca de su actuación. ${ }^{38}$ Esta figura institucional sirvió de modelo primero a los curiosi y luego a los agentes in rebus. No era novedoso el cargo de magister officiorum, que debía de existir ya en época de Diocleciano, aunque Constantino reforzó sus atribuciones. Como ya se ha indicado, en 320 ya era el encargado de recibir precisamente la correspondencia administrativa imperial y de gestionarla en las oficinas palatinas..$^{39}$ Otro ejemplo de innovación institucional es la introducción de los comites con jurisdicción diocesana. Una ley de 318 atestigua que el Octaviano, comes Hispaniarum, atendía las causas más graves, tales como los crímenes -en concreto, el de rapto de doncellas-, que implicaban a senadores. ${ }^{40}$

Sin embargo, en este período se libraron, sobre todo, provisiones relativas a la administración de justicia. Al emperador se le podían dirigir todas las consultas necesarias relativas a causas de naturaleza civil, como señaló en una provisión de $318 .{ }^{41}$ Esto no le impidió prohibir que las querellas sobre las que ya se hubiera pronunciado volvieran a ser sometidas a instrucción judicial, toda vez que se consideraban resueltas. ${ }^{42}$ No obstante, por exigencias de la práctica, estableció en este mismo período algunas limitaciones al respecto. La primera, comprendida en una provisión de 319 , contemplaba que no podrían enviársele los casos ya sentenciados o que no ofrecieran márgenes de duda. ${ }^{43}$ La segunda, que figuraba en una ley de 321, prescribía entre los requisitos para elevarle una consulta que el examen de la causa debería haber concluido ante el juez instructor. ${ }^{44}$ De acuerdo con la misma lógica, si el juez había dictado sentencia, ya no podría solicitar la intervención imperial ${ }^{45}$ Con todo, aumentó en 319 el plazo establecido para requerirle una resolución sobre un caso concreto a veinte días, a diferencia de los quince estipulados en 313, probablemente siguiendo criterios de racionalización administrativa. ${ }^{46}$ En función de los mismos, determinó algunos casos en los que no era procedente que los jueces reclamaran su interven-

37 CTh. 12, 1, 1.

38 CTh. 15, 1, 2. Cf. Porena 2003, 377-378.

39 CTh. 16, 10, 1. Cf. De Bonfils 1981, 60-61; Delmaire 1995, 75. Sobre el cargo en cuestión, véase: Clauss 1980; Aiello 2001; Castello 2010; ID. 2012, 326-364.

40 CTh. 9, 1, 1 (Br. 9, 1, 1). Cf. WieWIEROWSKi 2006.

41 CTh. 9, 1, 1 (Br. 9, 1, 1).

42 CTh. 11, 30, 9. Cf. Dillon 2012, 308.

43 CTh. 11, 29, 2 (319).

44 CTh. 2, 18, 1 (321): (...) nec ad nos mittatur aliquid quod plena instructione ingideat. Cf. Dillon 2012, 203, 244.

45 CTh. 11, 29, 2 (319).

46 CTh. 11, 30, 8 (319). Cf. Dillon 2012, 206-207. 
ción. Por ejemplo, la ya comentada carta dirigida al comes Hispaniarum Octaviano en 318 disponía que los casos de senadores enjuiciados en las provincias por causas criminales no le fueran comunicados al emperador. ${ }^{47}$ También prohibió en 320 que se le remitieran casos sin responsable conocido ni aquellos cuyo proceso no hubiera finalizado ante el juez. ${ }^{48}$

Por el contrario, indicó específicamente algunas cuestiones sobre las que requería ser informado sin excepción. En primer lugar, por orden cronológico, se encontraban las manumisiones. En efecto, estableció en 319, en una ley dirigida a Baso, prefecto de Roma, que, en cuanto se le reconociera a alguien la libertad, el príncipe debía ser informado al respecto. Sin embargo, la misma norma especificaba que un liberto, aunque pudiera demostrar que había recibido la manumisión por quien no era su propietario legal, debería ser devuelto a su dueño, y éste, además, tendría que ser indemnizado con otro esclavo de igual sexo y edad. ${ }^{49}$ Después, entre las prioridades políticas del emperador estaba el control de los recursos económicos, vitales en una época prebélica. Lo demuestra una instrucción dirigida en 319 a Verino, vicario de África, que establecía que el emperador también debía ser enterado de la requisa de los bienes de los decuriones juzgados culpables de falsificar moneda. ${ }^{50}$

Dentro de la disparidad de cuestiones acerca de las que el emperador ordenaba estar informado, hay un aspecto común a todas, que era la necesidad de garantizar el control imperial de algunos aspectos de la administración de justicia, como eran los pleitos sobre la condición de las personas y los ingresos en concepto de ejecución de penas pecuniarias. Conviene advertir que la política de Constantino en todo lo concerniente a la gestión de los asuntos públicos difería de modo considerable de la desarrollada por Licinio. El cuñado de Constantino se atuvo a la práctica política de la Tetrarquía. De este modo, sin perjuicio de establecer normas, dejó un amplio margen de actuación a los magistrados a efectos de aplicarlas. ${ }^{51}$ Servirá para ilustrar este rasgo particular de la administración tetrárquica recordar la desigual aplicación de los edictos persecutorios. En concreto, Constancio Cloro se limitó a privar a las iglesias de sus bienes, respetando las vidas de clérigos y laicos. ${ }^{52}$ El padre de Constantino también llevó a cabo una política fiscal en Galia caracterizada por aliviar la presión fiscal sobre los ciudadanos. ${ }^{53}$ Quizás prevenido acerca de los efectos contraproducentes de la falta de vigilancia imperial de la gestión llevada a cabo por los gobernadores provinciales, Constantino demostró entre 313 y 321 un constante interés por saber si sus provisiones se aplicaban y cómo. Se podría presumir que esta actitud tenía fines

47 CTh. 9, 1, 1 (Br. 9, 1, 1).

48 CTh. 9, 34, 3 (320).

49 CTh. 4, 9, 1 (CI. 7, 10, 7).

50 CTh. 9, 21, 1. Sobre Verino, cf. ARnHEIM 1972, 64-65.

51 Esta actitud administrativa se puede apreciar en su política religiosa. Licinio no fue un perseguidor, pero, a partir del año 320, conforme se deterioraban definitivamente sus relaciones con Constantino, comenzó a librar medidas que imponían algunas limitaciones a la práctica del cristianismo (Euseb. Caes., VC, 1, 51; 1, 53). En este contexto, el gobernador de la provincia de Helenoponto hizo ejecutar al obispo Basilio de Amasea Póntica y ordenó destruir las iglesias de la ciudad (Euseb. Caes., HE, X, 8, 15; Euseb. Caes., VC, II, 1, 2; Hieron., Chron., CCLXXV Olymp. XIIII). Sobre estas medidas, cf. Moreno Resano 2009, 170, n. 13.

52 Lact., De mort. pers., XV, 7. Sobre la política religiosa de Constancio, véase: SмIтH 1997.

53 Eutrop., X, 2. 
propagandísticos, para presentarse como un atento gobernante frente a la desatención de los asuntos públicos por parte de su adversario. Sin embargo, todas las provisiones comentadas, con excepción de la dirigida a los veteranos galos, estaban destinadas a magistrados y oficiales, luego no se preveía que tuvieran circulación fuera del ámbito burocrático. Este hecho constata que Constantino quería atender en persona algunos negocios para controlar mejor los territorios bajo su autoridad.

\subsection{El tercer período (324-331)}

Después de la derrota de Licinio en 324, el número de cláusulas incluidas en las leyes que exigían ser notificadas al príncipe disminuyó significativamente. En ello influyó no sólo la unificación de las provincias orientales y occidentales bajo el poder de un único Augusto, sino también la reestructuración administrativa llevada a cabo por Constantino. En efecto, desde 324 hasta 337 casi todas las leyes imperiales que obligaban a notificar al emperador ciertos asuntos estaban dirigidas a prefectos del pretorio o prefectos de la ciudad de Roma, quienes asumieron la responsabilidad de administrar justicia y ejecutar las órdenes imperiales, en tanto que las decisiones políticas se convirtieron en una competencia exclusiva del emperador y de su comitatus palatino. ${ }^{54} \mathrm{El}$ cambio más significativo del período abierto con la conquista de las provincias orientales se concretó en que, a diferencia de la etapa anterior, Constantino reservó la responsabilidad directa de instruir causas, en primera instancia, a los gobernadores provinciales y, en segunda, a los prefectos del pretorio. El emperador intervino a partir de entonces en asuntos judiciales sólo excepcionalmente, cuando se producían negligencias o casos de prevaricación, es decir, cuando los cauces procesales ordinarios no funcionaran. Esta actitud no era novedosa, ya que en 318 ya había comunicado al comes Hispaniarum que no le enviara las causas relativas a senadores juzgados por crímenes. ${ }^{55}$ Pero esta norma no fue definida hasta el año 325 , cuando cursó un edicto, publicado en Antioquía, que estipulaba que si las apelaciones no eran atendidas por el gobernador provincial, debían ser enviadas al prefecto del pretorio, y, si éste comprobaba que el gobernador había actuado por negligencia, tenía que ponerlo en conocimiento del príncipe. ${ }^{56}$ Aunque expuestas en forma de edicto, estas normas nunca estuvieron completamente claras. Por eso Constantino reiteró en 328 a Máximo, prefecto de Roma, la instrucción de que si un gobernador actuaba con negligencia, debía comunicárselo. ${ }^{57}$ Un año después dirigió al nuevo prefecto de Roma, Anicio Juliano, una carta, en la que le señalaba que las apelaciones de índole fiscal eran competencia del prefecto de la ciudad, quien, una vez se hubiera pronunciado, debía comunicar su fallo al príncipe. ${ }^{58}$ Ese mismo año, y en términos muy similares, aunque en tono más conminatorio, usando el plural mayestático, volvió a recalcarle

54 Cf. n. 39.

55 CTh. 9, 1, 1.

56 CTh. $1,5,1$.

57 CTh. 1, 16, 4. Cf. Dillon 2012, 197.

58 CTh. 11, 30, 18. 
a Juliano que correspondía al prefecto atender las apelaciones y que no debía enviárselas a él. ${ }^{59}$

Aunque las estipulaciones que hacían responsables a los gobernadores provinciales, al prefecto de Roma y a los prefectos del pretorio de la atención de las apelaciones eran muy explícitas, no le faltaban a Anicio Juliano razones para ser prudente y remitir al emperador cualquier asunto judicial problemático. Constantino había requerido en numerosas ocasiones, antes de 324 , tener conocimiento directo de las causas judiciales. Nótese, en cualquier caso, que estas advertencias tuvieron una difusión limitada, ya que fueron enviadas al prefecto de Roma. Probablemente sea ésta la razón por la que en 331 volvió a recordar en un edicto dirigido ad universos provinciales que la resolución de apelaciones competía, primero, a los gobernadores provinciales, a los comites y a los vicarios de los prefectos del pretorio, y, en última instancia, a los prefectos del pretorio. En el caso de que los prefectos del pretorio dieran la razón a los demandantes, debía ser denunciado al emperador el juez que hubiera desatendido el recurso. ${ }^{60}$ En otro fragmento del mismo texto, Constantino exhortaba a los ciudadanos a denunciar los posibles casos de prevaricación imputables a jueces, comprometiéndose a hacerlos investigar diligentemente por los prefectos del pretorio y los comites, con la advertencia de que algunas acusaciones podían ser falsas y haber sido urdidas sirviéndose de clientes que actuaban de acusadores. ${ }^{61} \mathrm{La}$ reiteración de las resoluciones, ya estipuladas en el edicto de 325 , cobra sentido en el contexto de la transformación de la prefectura del pretorio de un cargo con competencias ministeriales en una figura administrativa con competencias territoriales a partir de $329 .{ }^{62}$

Como se ha podido comprobar, Constantino se desentendió de la responsabilidad de dirimir directamente las acciones judiciales, aunque se reservó la facultad de resolver algunos litigios. En efecto, estableció en una ley dirigida en 326 al prefecto de Roma Acilio Severo que cualquier litigio sobre la propiedad de una donación imperial era competencia exclusiva del príncipe. ${ }^{63}$ También prescribió en una carta enviada en 329 al prefecto del pretorio de Oriente Evagrio que los jueces ordinarios no resolvieran las demandas de los curiales que quisieran quedar exonerados de sus cargas contributivas por razón de no poderles hacer frente. Estos supuestos debían serle comunicados directamente al emperador, que se declaraba la única persona competente para resolverlas. ${ }^{64}$

Circunstancialmente, Constantino exigió ser informado acerca de la ejecución de algunas de sus órdenes. Lo hizo, en concreto, en dos cartas imperiales enviadas al obispo de Jerusalén, Macario. La primera, datada entre 324 y 326, hace referencia a

59 CTh. 11, 30, 13. La data de la ley la fecha en 339, y también figura a nombre de Constancio. Sin embargo, tanto el destinatario (Anicio Juliano) como el contenido de la ley advierten de que el texto corresponde a la cancillería constantiniana y que fue emitida inmediatamente después de CTh. 11, 30, 13.

60 CTh. 11, 30, 16.

61 CTh. 1, 16, 6 (CI. 1, 40, 3).

62 Porena 2003, 558-562.

63 CTh. 10, 8, 3 (Br. 10, 4, 1). Cf. Chastagnol 1962, 77.

64 CTh. 12, 1, 1 (Br. 12, 1, 1; CI. 10, 32, 14). La ley está datada en 313, pero debe de corresponder al año 329. Cf. Porena 2003, 419. 
la prohibición de celebrar ritos tradicionales dentro del complejo arquitectónico de la basílica cristiana que se debía construir en el solar que ocupaba el templo de Mambré, en Hebrón. El príncipe indicaba a Macario que los obispos de Palestina debían informarle de si se producía alguna infracción de sus prescripciones, para imponerle al culpable la pena capital. ${ }^{65}$ Resulta paradójico que en esta misiva el emperador se reservara la facultad de juzgar a quien contraviniese sus órdenes, toda vez que en 318 había establecido que las causas de índole criminal debían ser instruidas por el gobernador de la provincia donde se hubiera perpetrado la acción y, a lo sumo, por los comites imperiales con jurisdicción provincial. ${ }^{66} \mathrm{La}$ explicación parece encontrarse en el hecho de que las instrucciones enviadas dicho año al comes Hispaniarum Octaviano concernían a aquellos casos en los cuales el encausado tuviera que someterse a las leges publicae, tal y como especifica el texto en cuestión. En tales supuestos, el príncipe sólo debía ser informado de la sentencia. La carta dirigida a Macario plantea una situación distinta, pues, de acuerdo con sus estipulaciones, el acusado de cometer actos sacrílegos en el solar del templo de Mambré infringía de modo expreso la orden imperial. Constantino estaba interesado en que se acatara su prohibición de profanar la basílica, entre otras razones, porque las provisiones enviadas a Macario habían sido establecidas a ruegos de Eutropia, madre de la emperatriz Fausta. Por otra parte, en el contexto inmediatamente posterior a la derrota de Licinio, Constantino debía demostrar que no estaba dispuesto a tolerar ningún desafío a su autoridad, prescribiendo un castigo ejemplar para quienes no respetaran sus disposiciones. Es oportuno recordar que su cuñado, desposeído del título de Augusto, había sido confinado en Tesalónica, donde, después de intentar sublevarse, acabó siendo ejecutado en $325 .{ }^{67}$ Un año más tarde corrieron la misma suerte su hijo Licinio Liciniano, el hijo del propio Constantino, Crispo, y la emperatriz Fausta. ${ }^{68}$ Por otra parte, la prohibición puntual de celebrar ritos tradicionales en Mambré, so pena de muerte, aunque era una medida puntual y excepcional, suponía una confirmación del favor imperial hacia la jerarquía eclesiástica en Oriente. Y más, si se tiene en cuenta que la política religiosa de Constantino, a diferencia del sincretismo helenístico que había favorecido Licinio, estaba promoviendo la difusión del cristianismo, y, en su defecto, la observancia de la piedad tradicional grecorromana. ${ }^{69}$

También excepcional, aunque por ello, no menos significativa, fue la orden, comunicada también por carta a Macario de Jerusalén, para que le solicitara rápidamente por escrito los materiales arquitectónicos que considerara adecuados, precisando su calidad y cantidad, sin importar dónde se encontraran, para la construcción de la basílica de la Resurrección en Jerusalén. Aparece también en una carta dirigida al

65 Euseb. Caes., $V C$, III, 53, 2.

66 CTh. 9, $1,1$.

67 Origo, V (28-29); Eutrop., X, 6, 1; Hieron., Chron., CCLXXV Olymp. XVII; Paul. Oros., VII, 28, $20-21$.

68 Aurel. Vict., XLI, 11; Eutrop., X, 6, 3; Hieron. Strid., Chron. CCLXXVI Olymp. XX; De uit. et mor. imp., XLI, 11-12; Paul. Oros., VII, 28, 26. El silencio oficial impuesto sobre las ejecuciones explica la imprecisión y divergencias que presentan las fuentes conservadas. Sobre las mismas, véase: GuTHRIE 1966; POHLSANDER 1984.

69 Véase al respecto: Moreno Resano 2009. 
obispo Macario. ${ }^{70} \mathrm{Al}$ igual que en relación con el templo de Mambré, se trataba de una provisión excepcional. En el caso de la basílica hierosolimitana, según indica la carta, Constantino trataba de levantar allí un edificio que significara "el lugar más admirable del universo". ${ }^{71}$ De este modo, Jerusalén pasaba a ser reconocida como el axis mundi, el punto central del mundo conocido, por haber muerto y resucitado allí el Salvador. ${ }^{72}$ El emperador manifestaba estar personalmente interesado en la edificación de la iglesia, pues se hacía con fondos públicos, y que constituía una clara manifestación del trato privilegiado que dispensaba a la Iglesia, y más en particular, hacia el clero trinitario, pues la orden de construir la basílica fue librada dentro del clima inmediatamente posterior a la celebración del Concilio de Nicea. ${ }^{73}$

\subsection{Las intervenciones de Constante y Constancio II}

Como se ha podido comprobar, Constantino no volvió a hacer uso de estas estipulaciones después del año 331. Tampoco sus hijos lo hicieron cuando le sucedieron tras su muerte en 337. Constante envió en 348 una instrucción al Vicario de la diócesis de África, Cesoniano, en la cual le indicaba que los expedientes que le dirigieran los gobernadores y racioneros provinciales debían serle comunicados por medio de él, quien tenía que remitírselos con toda rapidez. ${ }^{74}$ Constancio II sólo adoptó una medida similar en 357, cuando pidió al prefecto del pretorio de Italia, Tauro, que los gobernadores no establecieran impuestos en las provincias que rigieran. En caso de ser necesario introducirlos, tenían que requerírselo al emperador enviándole la consulta por medio del prefecto del pretorio..$^{75}$ Todavía a título de mayor excepción, una carta de Constancio II del año 360 dirigida al prefecto de Roma Juliano, con vistas a otorgar la condición de senador al profesor de retórica de la ciudad más renombrado, solicitó que se le enviara una nómina de hombres de letras para deliberar quién era el más señalado para obtener dicho reconocimiento honorífico. ${ }^{76} \mathrm{~A}$ todas luces, esta medida trataba de introducir en el Senado romano un intelectual afín al emperador, del mismo modo que había sido nombrado Temistio miembro del Senado constantinopolitano. ${ }^{77}$ No obstante, también trató de extremar el control de la justicia y de sus responsables, en su caso, mediante la introducción de la figura institucional de los agentes in rebus. Una ley de 359 les encomendó de modo explícito la vigilancia de todos los asuntos políticos y de poner en su conocimiento las incidencias que surgieran, pero siempre a partir de la labor principal de supervisar el funcionamiento del cursus honorum (ad cursum regendum et curas agendas). ${ }^{78}$ Además, en 361, en conformidad con las medidas constantinianas, les advirtió de que cuando le llegara la

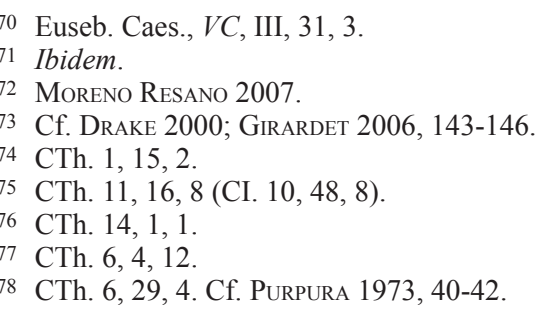


apelación de una sentencia de un prefecto del pretorio contra un militar, si se demostraba la culpabilidad del encausado, la pena establecida sería más rigurosa. ${ }^{79}$ En estos casos, los agentes in rebus tenían que aportar información adicional al emperador para que pudiera pronunciarse con relación a la causa en revisión. En general, Constancio II mantuvo la práctica constantiniana de dejar la administración de justicia en manos de los gobernadores provinciales, comites y vicarios diocesanos, y, en última instancia, de los prefectos del pretorio, atendiendo, en su lugar, cuestiones de índole estrictamente política.

\subsection{El principado de Juliano}

Juliano asumió la política administrativa de su tío. Sin embargo, si se atiende a Amiano Marcelino, ya desde su ejercicio de César en Galia se caracterizó por el desapego de la vida palatina y la dedicación a la gestión pública. ${ }^{80}$ Ya entonces, según el mismo historiador, se mostró bastante crítico con el comportamiento de los agentes in rebus, a quienes acusaba de malversar fondos públicos, $\mathrm{y}$, por extensión, de abusar de sus funciones. ${ }^{81}$ No en vano, en 363 prescindió de buena parte del personal de la schola, conservando únicamente a diecisiete agentes. ${ }^{82}$ Dentro de este planteamiento se comprende mejor su empeño en garantizar un funcionamiento más eficaz de las instituciones mediante las instrucciones que dirigió a sus prefectos Secundo y Mamertino. La ley cursada en 362 a Secundo, prefecto del pretorio de Oriente, reiteraba la prohibición constanciana de que los provinciales tuvieran que pagar impuestos $\sin$ conocimiento del emperador, al tiempo que obligaba a que las expensas destinadas a costear el funcionamiento debían ser asumidas por todos los possessores ${ }^{83} \mathrm{La}$ preocupación de Juliano hasta el momento de su muerte por la distribución equitativa de los impuestos, y, en particular, por que los más pudientes obtuvieran rebajas fiscales (indulgentiae), en perjuicio de los menos acomodados, fue también observada por Amiano. ${ }^{84}$ En realidad, según el mismo autor, esta política de alivio fiscal de los provinciales ya la había practicado en sus años de César, cuando impidió que el prefecto del pretorio de las Galias, Florencio, estableciera gravámenes extraordinarios. ${ }^{85}$ Ese mismo año de 362, envió al prefecto del pretorio del Ilírico, Mamertino, una instrucción destinada a los gobernadores provinciales que les exigía informar a los vicarios diocesanos de cuanto fuera puesto en conocimiento del propio prefecto y del emperador. ${ }^{86}$ Juliano, al igual que sus predecesores, también trató de supervisar el uso

79 CTh. 6, 29, 3.

80 Amm. Marc., 16, 5, 5.

81 Amm. Marc., 16, 5, 11.

82 Lib., Or. 2, 58; 18, 135. Cf. SAntos Yanguas 1977, 132. No obstante, a quienes abandonaron el servicio les compensó con el privilegio de ser dispensados de formar parte de las curias municipales, al igual que aquellos que hubieran estado durante más de tres años en la schola agentum in rebus (CTh. 6, 27, 2, de 363).

83 CTh. 11, 16, 10.

84 Amm. Marc., 16, 5, 15.

85 Amm. Marc., 17, 3 .

86 CTh. 1, 15, 4. Sobre la prefectura de Mamertino durante el principado de Juliano, cf. WIRBELAUER FLEER 1995. 
de los medios públicos, para evitar los abusos que frecuentemente se cometían. En concreto, envió a Mamertino una disposición que le exigía comunicarle los casos en los que los correos emplearan más caballos de postas de los necesarios para desempeñar sus servicios, pues había establecido para estos supuestos la pena capital en una adnotatio anterior. De ser necesario un animal más para tales efectos, el prefecto del pretorio era el responsable de decidir si debía asignarlo. Además, un agens in rebus vigilaría el correcto empleo de los caballos entrenados para el cursus publicus. ${ }^{87} \mathrm{La}$ realidad demuestra que Juliano, aunque reticente hacia la actuación burocrática de los agentes, no podía prescindir de ellos. Ante esta situación, optó por regular sus funciones para evitar malas prácticas.

Juliano, al igual que su tío, y desde que obtuvo el título de César, conforme a las pautas establecidas por la legislación precedente, no requirió ser informado del curso de ningún proceso. Atendió, sin embargo, algunas causas, a petición de los demandantes, aunque casi siempre falló en favor de los acusados. Por ejemplo, cuando los padres de una doncella raptada y violada le elevaron la causa, condenó al acusado a la relegatio, estando prevista para ese crimen la pena capital. La ley constantiniana de 318 impedía que estos casos fueran dirigidos al emperador. ${ }^{88}$ Juliano respondió que había actuado así por clemencia, puesto que él, príncipe con un talante moderado, estaba por encima de la severidad de la jurisprudencia. Así mismo, se mostró esquivo cuando se le dirigían reclamaciones judiciales, para cuyo examen remitía a los gobernadores provinciales, revisando en todo caso sus fallos con mayor indulgencia ${ }^{89}$ Incluso absolvió por falta de pruebas documentales a Numerio, gobernador de la Narbonense, juzgado en su presencia por apropiación indebida. ${ }^{90}$ Juliano no se negaba a instruir procesos judiciales por cuestiones graves, pero era reacio a adoptar sentencias condenatorias. En su caso, parece que quería evitar que se recurriera a él para fallar resoluciones singularmente duras y, más, cuando faltaban pruebas, y evitar así la manipulación política de la justicia, algo bastante evidente con relación al juicio de Numerio.

\section{Conclusiones}

Desde el año 313, algunas instrucciones imperiales destinadas a magistrados, oficiales y, a veces, obispos, contienen estipulaciones que exigían poner en directo conocimiento de los príncipes los particulares concernientes a la aplicación de determinadas medidas. Estas provisiones acostumbran a estar expresadas conforme a ciertas fórmulas cancillerescas, de las cuales, la más habitual era ad nostram scientiam referatur. Su empleo refleja el temperamento pragmático de Constantino, Constante, Constancio II y Juliano y que estaba orientado a obtener desde las oficinas palatinas una gestión eficaz de aspectos concretos de la administración provincial. En efecto,

87 CTh. 8, 5, 14 (CI. 12, 50, 4). Cf. Stoffel 1994, 43-51, 94-106.

88 CTh. 9, 1, 1.

89 Amm. Marc., 16, 5, 12-13.

90 Amm. Marc., 18, 1, 4. 
no todos los asuntos recibieron la misma atención ni de modo continuado. Constantino prefirió controlar personalmente el funcionamiento de la justicia desde el año 313 hasta la unificación del Imperio bajo su autoridad en 324. Entre esas fechas, a consecuencia de los problemas provocados por el conflicto donatista, y en los dos años que mediaron entre la derrota de Licinio y la crisis dinástica del año 326, también se preocupó, ocasionalmente, de vigilar la aplicación de disposiciones en materia religiosa. En particular, el emperador ordenó ser informado acerca de la devolución de las propiedades a la Iglesia y de la construcción de las basílicas de Mambré y la Anástasis de Jerusalén. El uso de las cláusulas analizadas se hizo cada vez más infrecuente a partir de 326, hasta desaparecer después de 331. Este cambio en la práctica administrativa parece deberse a que en esas mismas fechas Constantino delegó en los prefectos del pretorio la resolución de apelaciones, siguiendo el ejemplo de ciertas medidas que había adoptado entre 318 y 321 . Constancio II, aunque, a diferencia de su padre, recurrió muy eventualmente a introducir las prescripciones comentadas en sus leyes, supeditó la actuación de los jueces al control de los agentes in rebus. Juliano tampoco las incluyó habitualmente. Cuando lo hizo fue para garantizar que el reparto de las cargas fiscales fuera proporcional y para que no se produjeran abusos en el empleo de los recursos públicos. Frente a la insistencia de Constantino en ser informado de ciertos particulares, sus sucesores Constancio II y Juliano confiaron la supervisión de la ejecución de las leyes, por norma general, a los agentes in rebus.

Como se ha observado, los emperadores trataron de racionalizar mediante las cláusulas estudiadas unos recursos limitados, en términos humanos y económicos, que les permitían sólo vigilar directamente la aplicación de un reducido número de medidas. Cabe añadir a lo señalado que, en general, la implantación de las reformas burocráticas emprendidas desde época tetrárquica, continuada por Constantino y sus sucesores, planteó serias dificultades -manifestadas en distintas formas de corrupción o negligencia-, sobre todo, por la falta de aceptación tanto por parte de los magistrados y oficiales, como de la mayoría de los ciudadanos. ${ }^{91}$ En realidad, desaparecido el sistema tetrárquico, los emperadores estaban lejos de poder asumir directamente la ejecución de muchas de sus normas. Por esa razón, el empleo de las fórmulas que exigían informarles de asuntos muy particulares no desapareció, pero sí disminuyó notablemente. Frente a la imposibilidad de ejercer el control directo, llevado a cabo por correspondencia oficial, Constancio II y Juliano encomendaron a oficiales de su confianza la tarea de velar por el cumplimiento de sus órdenes.

\section{Bibliografía}

AiELLo, V. (2001): "I rapporti fra centro e periferia in epoca costantiniana: l'origine del magister officiorum", [en] Accademia Romanistica Costantiniana. XIII Convegno Internazionale, Napoli, 137-163.

91 SChuller 1975; Kelly 2004, 3-5, 182-183. 
Amelotti, M. (1975): “Tabellioni e documenti nell'età del dominato", [en] M. Amelotti - G. Costamagna, Alle origini del notariato italiano (=Studi storici sul notariato italiano 2), Roma (Milano, 1995²), 5-18.

Arcaria, F. (2000): Referre ad principem. Contributo allo studio delle epistulae imperiali in età classica, Milano.

Arnheim, M. T. W. (1972): The Senatorial Aristocracy in the Later Roman Empire, Oxford.

BABUT, E.-СН. (1914): Recherches sur la garde impériale et sur le corps d'officiers del'armée romaine aux IV et $V^{E}$ siècles (=Extrait de la Revue historique CXVI), Paris (trad. de S. Perea Yébenes, La guardia imperial y el cuerpo de oficiales del ejército romano en los siglos IV y $V$ d. C., Madrid, 2014).

Barnes, T. D. (1982): The New Empire of Diocletian and Constantine, Cambridge (Mass.)London.

BARone-Adesi, G. (1998): Ricerche sui corpora normativi dell'Impero romano. 1. I corpora degli iura tardoimperiali, Torino.

Buenacasa Pérez, C. (2011): “La «conversión» de Constantino I y su aproximación al cristianismo", [en] J. Á. Tamayo Errazquin (ed.), Cristianismo y mundo romano. Vy VI ciclos de conferencias sobre el mundo clásico, Vitoria, 145-169.

Carotenuto, E. (2002): “Six Constantinian Documents (Eus., H. E., 10, 5-7)”, VChr 56/1, 56-74 (http://dx.doi.org/10.1163/15700720252984837).

Castello, $\mathrm{M}^{\mathrm{a}} \mathrm{G}$. (2010): "Tribunus et magister officiorum: cause di un'omissione in Giovanni Lido", Koinonia 34, 161-180.

(2012): Le segrete stanze del potere. I comites consistoriani e l'imperatore tardoantico (=Il potere e il consenso. Collana di Storia romana 1), Roma.

Chastagnol, A. (1962): Les fastes de la Préfecture de Rome au Bas-Empire (=Études Prosopographiques II), Paris.

Christensen, T. (1984): “The So-Called Edict of Milan”, C\&M 35, 129-175.

Christol, M. (1988): "Une correspondance impériale: testimonium et suffragatio dans la Table de Banasa", $R D$ 66, 31-42.

Clauss, M. (1980): Der magister officiorum in der Spätantike (4.-6. Jahrhundert). Das Amt und sein Enfluß auf die kaiserliche Politik (=Vestigia 32), München.

Corcoran, S. (1996): The Empire of the Tetrarchs. Imperial Pronouncements and Government. AD 284-324, Oxford.

De Bonfils, G. (1981): Il comes et quaestor nell'età della dinastia costantiniana (=Pubblicazioni della Facoltà giuridica dell'Università di Bari 62), Napoli.

Delmaire, R. (1995): Les institutions du Bas-Empire romain, de Constantin à Justinien: les institutions civiles palatines, Paris.

Dillon, J. N. (2012): The Justice of Constantine. Law, Communication and Control, Ann Arbor.

Di Maio, M. - Zeuge, J. - Bethune, J. (1990): “Proelium Cibalense and Proelium Campi Ardiensis: The First Civil War of Constantine I and Licinius I", AncW 21, 67-91.

Drake, H. A. (2000): Constantine and the Bishops. The Politics of Intolerance, Baltimore. 
Dupont, CL. (1971): “Constantin et les constitutions impériales”, [en] Studi in onore di Edoardo Volterra, Milano, vol. I, 549-569.

Elliott, T. G. (1996), The Christianity of Constantine the Great, Scranton.

Gaudemet, J. (1982): "Privilèges constantiniens en faveur des militaires et des vétérans", [en] Studi in onore di Cesare Sanfilippo II (=Pubblicazioni della Facolta di Giurisprudenza di Catania 96), Milano, vol. II, 177-190.

Giardina, A. (1977): Aspetti della burocrazia nel Basso Imperio (=Filologia e critica 22), Roma.

GiRARDET, K. M.

(1992): “Das Reichskonzil von Rom (313)-Urteil, Einspruch, Folgen”, Historia 41, 104116.

(2006): Die konstantinische Wende. Voraussetzungen und geistige Grundlagen der Religionspolitik Konstantins des Großen, Darmstadt.

Guthrie, P. (1966): “The Execution of Crispus", Phoenix 20, 325-331 (http://dx.doi. org/10.2307/1087057).

Harries, J. (1988): “The Roman Imperial Quaestor from Constantine to Theodosius II", JRS 78, 148-172 (http://dx.doi.org/10.2307/301455).

Honig, R. M. (1960): Humanitas und Rhetorik in spätrömischen Kaisergesetzen. Studien zur Gesinnungsgrundlage des Dominats, Göttingen.

Kelly, Chr. (2004): Ruling the Later Roman Empire (=Revealing Antiquity 15), Cambridge, Mass.

Kunoff, W. (2001): Diokletian und die Epoche der Tetrarchie. Das römische Reich zwischen Krisenbewältigung und Neuaufbau (284-313 n. Chr.), Berlin.

Maraval, P. (2011): Constantin le Grand, Paris.

Millar, F. (1977): The Emperor in the Roman World (31 BC-AD 337), London.

Moreno Resano, E.

(2007): "El destino de los cultos tradicionales semíticos: Constantino y la destrucción de templos en Palestina, Fenicia y Cilicia”, [en] J. J. Justel - B. E. Solans et alii (eds.), Las aguas primigenias. El Próximo Oriente Antiguo como fuente de civilización. Actas del IV Congreso Español de Próximo Oriente Antiguo II, Zaragoza, 457-477.

(2009): "La política religiosa y la legislación sobre los cultos tradicionales del emperador Licinio (306-324)", Polis 20, 167-207.

(2013): "Constantino y su relación personal con el cristianismo: de la piedad tradicional a la conversión”, 'Ilu 18, 175-200 (http://dx.doi.org/10.5209/rev_ILUR.2013.v18.43047).

Odahl, CH. M. (2004): Constantine and the Christian Empire, London.

Pietri, Chr. (1978): Roma Christiana I, Roma.

Pohlsander, H. A. (1984): “Crispus: Brilliant Career and Tragic End”, Historia 33, 79-106.

PorenA, P. (2003): Le origini della prefettura del pretorio tardoantica (=L'Erma di Bretschneider, Saggi di Storia antica 20), Roma.

PurpurA, G. (1973): "I curiosi e la schola agentum in rebus", ASGP 34, 165-285 [5-113].

Schuller, W. (1975): “Grenzen des spätrömischen Staates: Staatspolizei und Korruption”, ZPE 16/1, 1-21

Smith, M. D. (1997): “The Religion of Constantius I”, GRBS 38, 187-208. 
Stoffel, P. (1994): Über die Staatspost. Die Ochsengespanne und die requirierten Ochsengespanne des römischen Postwesens auf Grund der Gesetze des Codex Theodosianus und Codex Iustinianus (=Europäische Hochschulschriften 595), Bern a. A.

SAntos Yanguas, N. (1977): "El servicio policial secreto romano en el Bajo Imperio según Amiano Marcelino", MHA 1, 127-149.

VAN DAM, R. (2003): “The Many Conversions of the Emperor Constantine", [en] K. Mills - A. Grafton (eds.), Conversion in Late Antiquity and the Early Middle Ages: Seeing and Believing (=Studies in Comparative History 4), Rochester, 127-151.

Wiewierowski, J. (2006): "Octavianus-the Special Envoy of Constantine the Great (Some Remarks)”, Gerión 24/1, 325-340.

Wirbelauer, E. - Fleer, Chr. (1995): “Totius orbis Augustus. Claudius Mamertinus als praefectus praetorio der Kaiser Julian und Valentinian", [en] M. Weinmann-Walser (ed.), Historische Interpretationen: Gerold Walser zum 75. Geburtstag dargebracht von Freunden, Kollegen und Schüllern (=Historia/Einzelschriften 100), Stuttgart, 191-201. 